\title{
The Role of Substance P in Secondary Pathophysiology after Traumatic Brain Injury
}

\author{
Robert Vink ${ }^{1 *}$, Levon Gabrielian ${ }^{2}$ and Emma Thornton ${ }^{2}$ \\ 'Sansom Institute for Health Research, University of South Australia, Adelaide, SA, Australia, ${ }^{2}$ Discipline of Anatomy and \\ Pathology, Adelaide Medical School, University of Adelaide, Adelaide, SA, Australia
}

It has recently been shown that substance $\mathrm{P}(\mathrm{SP})$ plays a major role in the secondary injury process following traumatic brain injury (TBI), particularly with respect to neuroinflammation, increased blood-brain barrier (BBB) permeability, and edema formation. Edema formation is associated with the development of increased intracranial pressure (ICP) that has been widely associated with increased mortality and morbidity after neurotrauma. However, a pharmacological intervention to specifically reduce ICP is yet to be developed, with current interventions limited to osmotic therapy rather than addressing the cause of increased ICP. Given that previous publications have shown that SP, NK1

Edited by:

Eric Peter Thelin, University of Cambridge, United Kingdom

Reviewed by: Fredrik Clausen, Uppsala University, Sweden David J. Loane, University of Maryland School of Medicine, United States Anders Hånell, Karolinska Institutet, Sweden

*Correspondence: Robert Vink robert.vink@unisa.edu.au

Specialty section: This article was submitted to Neurotrauma a section of the journal Frontiers in Neurology

Received: 02 April 2017 Accepted: 13 June 2017 Published: 28 June 2017

Citation: Vink R, Gabrielian L and Thornton E (2017) The Role of Substance $P$ in Secondary Pathophysiology after Traumatic Brain Injury. Front. Neurol. 8:304. doi: 10.3389/fneur.2017.00304 receptor antagonists reduce edema after $\mathrm{TBI}$, more recent studies have examined whether these compounds might also reduce ICP and improve brain oxygenation after TBI. We discuss the results of these studies, which demonstrate that NK1 antagonists reduce posttraumatic ICP to near normal levels within $4 \mathrm{~h}$ of drug administration, as well as restoring brain oxygenation to near normal levels in the same time frame. The improvements in these parameters occurred in association with an improvement in BBB integrity to serum proteins, suggesting that SP-mediated increases in vascular permeability significantly contribute to the development of increased ICP after acute brain injury. NK1 antagonists may therefore provide a novel, mechanistically targeted approach to the management of increased ICP.

Keywords: substance $P$, traumatic brain injury, edema, intracranial pressure, brain oxygenation, sheep model

Traumatic brain injury (TBI) has been identified as one of the leading causes of death and disability in individuals less than 40 years of age in developed countries $(1,2)$. Despite the significance of this public health issue, there is currently no accepted therapy that can improve outcome (3), largely because the pathophysiological factors and their mechanistic interaction in the injury process have not been well characterized. In addition to the primary (mechanical) injury caused at the time of the traumatic event, secondary injury factors play a major role in resultant neuronal cell death that results in lifelong disability experienced by many survivors. While a number of secondary injury factors have been identified $(4,5)$, water accumulation, or brain edema, has been recognized as being closely associated with patient outcome (6). Indeed, up to half of all deaths following TBI having been attributed to brain edema $(7,8)$. A number of treatment strategies have been introduced to relieve edema-associated brain swelling (9); however, these target the end result of the edematous process [increased intracranial pressure (ICP)] rather than the cause. These strategies include administration of hyperosmotic agents and barbiturates, hypothermia, hyperventilation, cerebrospinal fluid (CSF) drainage, and decompressive craniotomy (10). However, significant improvements in patient 
mortality and morbidity have not been observed with these interventions, largely because they do not attenuate the specific mechanisms associated with edema formation after TBI.

Increased ICP can locally compress tissue, reduce cerebral perfusion, reduce brain oxygenation with resultant hypoxia and ischemia, result in brain herniation and, in severe cases, cause death. For ICP to increase after TBI, the volume within the confines of the skull must increase either through vasodilation, hemorrhage, increased CSF production, reduced CSF reabsorption, or edema. If ICP is increased because of edema, it follows that the total fluid volume of the cranial vault must have increased, and the only source of this water can be the vasculature $(11,12)$. Water movement from the cerebral vasculature to the brain parenchyma is known as vasogenic edema and has been well described as a significant component of early edema formation after TBI (6). Moreover, vasogenic edema is known to be permissive for subsequent cytotoxic edema (13), which then initiates a feedback loop that further drives increases in vasogenic edema and consequently ICP (12). Vasogenic edema requires that there is increased blood-brain barrier (BBB) permeability to serum proteins. A net movement of water from the vascular compartment then follows extravasation of blood plasma proteins into the brain parenchyma, leading to a disruption of fluid homeostasis. Given the increase in the volume of the brain tissue under these circumstances, ICP rises and negatively influences patient outcomes (14). In addition, the loss of barrier integrity following acute injury to the brain allows peripheral immune cells to cross the barrier and further contribute to and exacerbate the inflammatory processes within the brain (15).

Increased BBB permeability after TBI with subsequent edema formation has been recently linked to substance P (SP) release $(16,17)$. Moreover, the increased BBB permeability and edema formation after acute brain injury, together with the associated increased ICP, was reduced by administration of a SP, NK1 receptor antagonist (17-19). Accordingly, the current review focuses on the role of SP in TBI, particularly in relation to edema formation and increased ICP.

\section{SUBSTANCE P}

Substance $\mathrm{P}$ is peptide of 11 amino acids and belongs to the large tachykinin peptide family containing over 40 tachykinins, including neurokinin $\mathrm{A}$, neurokinin $\mathrm{B}$, neuropeptide- $\gamma(\mathrm{NP} \gamma)$, and the recently identified hemokinin 1 . Originally identified in the 1930s by von Euler and Gaddum for its potent smooth muscle and hypotensive properties (20), SP is now known as a neurotransmitter that is released from primary afferent neurons in both the peripheral and central nervous system, as well as from non-neuronal cells such as inflammatory and endothelial cells $(21,22)$. In the nervous system, SP is localized to nuclei such as the substantia nigra and the medial amygdaloid nucleus, as well as to capsaicin-sensitive sensory neurons (23) where it is released in response to stimulation of the transient receptor potential channels by mechanical stimulation, temperature, $\mathrm{pH}$ changes, and ligand binding (24). Following release, SP can bind to tachykinin NK receptors to exert direct postsynaptic actions as a neurotransmitter or modulate other non-neuronal targets (22). The
NK receptors are 7-transmembrane domain, G-protein-coupled receptors, with three, known as the NK1, NK2, and NK3 receptor, having been identified to date (21). Each of the tachykinin neuropeptides is able to bind all three receptor types depending on receptor availability and concentration of the neuropeptide, indicating that there is a degree of cross-reactivity among the receptors (21). SP normally has the highest affinity for the NK1 receptor, which given the predominance of the NK1 receptor in the adult brain (25) makes SP the tachykinin of particular interest in the context of CNS injury.

\section{Synthesis}

Two genes exist that are relevant to tachykinin synthesis, namely the preprotachykinin (PPT) A gene and the PPTB gene. Four different forms of mRNA are expressed through alternative splicing from the PPTA gene (26), the $\alpha$ and $\delta$ forms exclusively encoding for the synthesis of SP, while the $\beta$ and $\gamma$ forms encode synthesis of SP, as well as NKA, neuropeptide K (NPK), and NP $\gamma$; NPK and $\mathrm{NP} \gamma$ are elongated forms of NKA. In the brain, $\alpha$ PPTA expression is predominant, while in the peripheral tissues, $\beta$ PPTA and $\gamma$ PPTA mRNAs are abundant (27). The PPTB gene encodes neurokinin B (22).

Similar to all neuropeptides, SP is synthesized on ribosomes that are exclusively present in the cell body. The mRNA encoding the tachykinin is initially translated into a larger protein precursor from which SP is subsequently released by the actions of proteases called convertases. Cleavage points for the convertases are doublets of cationic residues (26). After release, the actions of tachykinins are terminated by diffusion away from the receptor site or degradation by extracellular peptidases, the slow nature of these processes accounting for their prolonged effects (28).

\section{Metabolism}

Several enzymes are associated with SP metabolism including neutral endopeptidase (NEP) (29), angiotensin-converting enzyme (ACE) (30), SP-degrading enzyme (31), post-proline endopeptidase (32), dipeptidyl aminopeptide IV (33), cathepsinD (34), and cathepsin-E (35). The individual cellular localization of NEP and/or ACE suggests that these enzymes are most likely responsible for the in vivo cleavage of SP (36), albeit that all of these enzymes have been shown to cleave the tachykinin in vitro. Hydrolysis of SP by both ACE and NEP removes the carboxyl terminal required for binding to the tachykinin receptors (30). NEP hydrolyzes SP in the peripheral tissues, brain, and spinal cord (37-39) with ACE-degrading SP in the plasma, CSF, and the substantia nigra (40), as well as contributing to the degradation of peptide fragments released by NEP.

\section{Localization}

Immunohistochemistry has shown that SP is present in the diencephalon, telencephalon, rhinencephalon, hippocampus, basal ganglia, pons, amygdala, hypothalamus, septal areas, myelencephalon mesencephalon, metencephalon, and spinal cord (41). SP immunopositive nerve fibers are common in most autonomic ganglia (42-44) and are detected in trigeminal and dorsal root ganglia $(45,46)$ as well as in intrinsic neurons of the gut $(47)$. It is thought to play a modulatory role in the autonomic ganglia, the 
best characterized response being observed in guinea pig inferior mesenteric ganglion where SP mimics a slow depolarization that can be evoked by repetitive afferent nerve stimulation (48). Peripheral inflammation has been shown to increase SP immunoreactivity in the superficial layers of the spinal cord (49) and increase release of SP (50). Damage to neurons or their intense activation also induces neuropeptide gene expression leading to alterations in neuropeptide biosynthesis (51). Specifically, during noxious stimulation or neurogenic inflammation in the periphery, there is an upregulation (28) of PPT mRNA expression (52) and NK1 receptor mRNA (53).

\section{NEUROGENIC INFLAMMATION}

Sensory nerve fibers positive for both SP and calcitonin generelated peptide (CGRP) are found surrounding most blood vessels throughout the body. In particular, cerebral arteries have a rich supply of sensory neurons, suggesting that they have a role as mediators of the inflammatory process following injury. The release of these neuropeptides, including SP, is neurally elicited and results in a painful local inflammatory response known as neurogenic inflammation, characterized by increased vascular permeability, protein extravasation, mast cell degranulation, and vasodilation (54). These changes in vascular permeability and in blood vessel diameter result in localized swelling of the tissue (54). Also occurring are tissue-specific responses to neuropeptide stimulation including constriction of the bronchioles in the airways and contraction and/or relaxation of the smooth muscle in the bladder. SP is also widely considered to be the most active mediator of neurogenic inflammation, even though it is well known that other neuropeptides such as CGRP are involved. Nonetheless, CGRP potentiates the effects of SP by enhancing the bioavailability of SP through competition with SP for metabolism by endopeptidases and by increasing the expression of the NK1 tachykinin receptor (55). Neurogenic inflammation in itself also leads to an increase in the PPTA and NK1 receptor mRNA transcript (28), which encodes SP and its primary receptor, respectively.

A role for classical inflammation in the pathophysiology of secondary injury following TBI is well known (15); however, brain neurogenic inflammation has remained relatively unexplored until recently. First characterized in peripheral tissue, neurogenic inflammation has now been well described in a number of studies following acute brain injury $(3,16,56)$. Its occurrence in the CNS was first demonstrated when electrical or chemical stimulation of the Dura mater, or acute capsaicin administration (a TRPV1 agonist), produced a local neurogenic inflammatory response in the form of increased protein extravasation that was not observed in the brain parenchyma itself or in the Pia mater (57). Subsequently in stroke, activation of endothelial NK1 receptors on blood vessels was shown to contribute to cerebral edema (58). Administration of SP was then shown in rats to produce a profound increase in plasma protein extravasation in the Dura mater, which was blocked when an NK1 receptor antagonist was administered and exacerbated by administration of either NEP or ACE inhibitors (59). In studies of TBI, inhibition of posttraumatic neurogenic inflammation by prior depletion of sensory neuropeptides using chronic capsaicin pretreatment attenuated increased BBB permeability, and the development of edema and functional deficits $(60,61)$, with subsequent studies demonstrating that ACE inhibitors exacerbated histological damage and functional deficits after TBI (62). Further studies in stroke established that reversible ischemic stroke resulted in increased brain perivascular immunoreactivity to SP with associated edema formation (63), while decreased SP immunoreactivity in association with increased NK1 immunoreactivity in both rat and human spinal cord injury suggested a role for neurogenic inflammation in this form of CNS injury $(64,65)$. Finally, activation of the multimodal TRPV1 receptor that is linked to SP release initiates neurogenic inflammation and is associated with increased BBB permeability, an effect abolished by the TRPV1 antagonist capsazepine and by an NK1 antagonist (66). Collectively, these data provide strong support that neurogenic inflammation involving the release of SP can occur within the setting of acute CNS injury.

\section{SP IN TBI}

Our own studies have shown that SP release is a ubiquitous feature of TBI and is associated with marked increases in BBB permeability, edema formation, and the development of functional deficits (56). Specifically, an increase in cerebral perivascular SP is observed following TBI as early as $5 \mathrm{~h}$ after TBI and persisting for at least $24 \mathrm{~h}$ following trauma (17). In human postmortem TBI tissue, the increased SP immunoreactivity colocalized with APP in perivascular nerve fibers suggesting that injury to these perivascular neurons was associated with SP release (67). The authors also reported that increased SP was apparent in cortical neurons and astrocytes, similar to observations made in the rodent models (17). SP mRNA levels as determined by PCR analysis remained elevated until at least 3 days posttrauma (68), suggesting persistent synthesis and release over this time frame. Moreover, serum levels of SP were elevated after TBI, with significant increases observed in both experimental (17) and human TBI, the latter having been associated with increased severity and mortality in patients (69). As discussed earlier, when SP catabolism is inhibited by the administration of an ACE inhibitor, further increases in SP immunoreactivity is observed together with an exacerbation of injury and neurological dysfunction (62).

Such increases in SP levels following trauma have been associated with increased permeability of the BBB and the formation of cerebral edema (12). Specifically, increased perivascular SP immunoreactivity after TBI colocalized with increased extravasation of Evan's blue dye, a marker of increased BBB permeability (17). The authors proposed that where SP was bound to a vascular endothelial cell, BBB permeability to vascular protein was increased. This increased BBB permeability to proteins was associated with the development of cerebral vasogenic edema, together with the development of persistent motor and cognitive deficits (17).

Further evidence supporting a role for SP in neurogenic inflammation after TBI has been obtained using NK1 antagonists (3). For example, the NK1 tachykinin receptor antagonist $N$-acetyl-L-tryptophan (NAT) attenuated increased BBB permeability, cerebral edema, and functional deficits when administered 
at 30 min after TBI (17). Attenuation of BBB permeability toward Evan's blue was dose dependent and used to determine the optimal dose. The therapeutic window of the antagonist was established as $12 \mathrm{~h}$ with rats administered with the compound at such delayed time points still demonstrating reductions in neuronal injury and an improvement in functional outcome (70). However, only a membrane permeable form of the drug was effective at these later time points, suggesting that the efficacy at delayed time points was dependent on central penetration of the compound. These studies also established that inactive enantiomers of the active ligands were ineffective irrespective of the time point, emphasizing that neuroprotective efficacy was dependent on actual binding to the NK1 receptor and the inhibition of its activity.

Most experimental studies are confined to male animals, largely to avoid the confounding effects of gender related hormones. However, the efficacy of the NK1 antagonists in TBI has also been demonstrated in female animals (71). Specifically, increased SP immunoreactivity was again apparent after diffuse TBI and the NK1 antagonist, NAT, reduced BBB permeability to albumin, reduced axonal injury, and significantly improved functional outcome. Moreover, it reduced edema formation at $24 \mathrm{~h}$ after TBI by more than $80 \%$. In related studies involving reversible ischemic stroke, administration of the NK1 antagonist at $4 \mathrm{~h}$ after stroke onset resulted in reduced $\mathrm{BBB}$ permeability and edema formation at $24 \mathrm{~h}$, plus improved functional outcome over 1 week (18). Indeed, treatment with the NK1 antagonist was more effective than neuropeptide depletion with capsaicin pretreatment (72) and importantly did not reduce the effectiveness of tissue plasminogen activator (tPA) treatment (73). When combined with tPA, the NK1 antagonist actually appeared to stabilize the $\mathrm{BBB}$ and extend the therapeutic window of the tPA treatment, which in clinical scenarios has been limited to $4 \mathrm{~h}$.

\section{ICP AND BRAIN OXYGENATION AFTER TBI}

Various animal models have been developed to reproduce aspects of the pathophysiology observed clinically after TBI, with rat models being the most widely used in experimental neurotrauma because they are considered cost effective and have readily available outcome measures (74). Disappointingly, however, treatments that have proven to be neuroprotective in these rodent models have not successfully translated to the clinical environment, thus emphasizing the importance of validating promising therapeutic agents in arguably more clinically relevant large animal models before progressing to clinical trials. Accordingly, we have developed a large animal model of diffuse TBI using sheep that reproduces consistent changes in ICP and brain tissue oxygenation $\left(\mathrm{P}_{\mathrm{bt}} \mathrm{O}_{2}\right)$ that are more representative of the clinical situation $(75,76)$. The use of a large animal, ovine model of TBI delivers a number of advantages that are not present in the more commonly used rodent models of TBI. First, there is the presence of a gyrencephalic brain with large white matter domains as opposed to a lissencephalic brain. The presence of gyri alters the mechanical response of the brain to TBI, while the large white matter domains alter the edema response. Sheep also have a significant tentorium cerebelli thus separating the brain into supratentorial and infratentorial compartments, similar to that observed in humans (77). These differences in cerebral folding, gray matter/white matter distribution, and brain compartmentalization may therefore contribute to the inability of some groups to consistently produce posttraumatic ICP responses in rats in the absence of mass lesions or hypoxia (78). Moreover, unlike rodents, sheep have remarkably similar ICP and $\mathrm{P}_{b t} \mathrm{O}_{2}$ values to humans, with normal ICP in the sheep between 6 and $9 \mathrm{~mm} \mathrm{Hg}$ and $\mathrm{P}_{\mathrm{bt}} \mathrm{O}_{2}$ being above $40 \mathrm{~mm} \mathrm{Hg}$, as well as the similar responses in these important physiological variables after TBI (75). Finally, large animals are amenable to using the same neurosurgical techniques and surgical instrumentation as that used clinically, which is also an advantage.

We have previously shown that ICP in moderate/severely injured sheep increases from control values of approximately $7 \mathrm{~mm} \mathrm{Hg}$ to above $20 \mathrm{~mm} \mathrm{Hg}$ within $1 \mathrm{~h}$ of the injury [(75); Figure 1A] and remains at those elevated levels in the hours that follow. This increase in ICP is consistent with the presence of vasogenic edema formation previously reported in diffuse TBI, and peaking between 4 and $6 \mathrm{~h}$ after injury $(79,80)$. Indeed, in the sheep brain, there was significant albumin extravasation at these early time points after TBI, confirming the presence of a more permeable BBB (80). When the NK1 antagonist, NAT, was administered at $30 \mathrm{~min}$ postinjury, there was a significant and sustained decline in ICP (19). Focusing on the time course of those previously reported changes [(19); Figure 1A], the NK1 receptor antagonist significantly reduced ICP by $32 \%$ within $3.5 \mathrm{~h}$ of administration, whereas ICP continued to increase by a further $36 \%$ in vehicle-treated animals. By $4 \mathrm{~h}$ after injury, ICP in the NK1-treated animals was half of vehicle-treated animals $(p<0.001)$ and approaching normal values (19).

The reoxygenation of brain tissue after TBI is an important part of effective therapeutic intervention, with restoration of aerobic energy metabolism essential to enable damaged tissue to recover. In the ovine model of diffuse TBI, injury typically results in a significant fall in $\mathrm{P}_{b t} \mathrm{O}_{2}$ to less than $50 \%$ of normal values, a reduction that persisted over the next few hours [(75); Figure 1B]. Administration of an $\mathrm{NK} 1$ receptor antagonist increased $\mathrm{P}_{\mathrm{bt}} \mathrm{O}_{2}$ to more than $80 \%$ of control values by $4 \mathrm{~h}$ after TBI (81), consistent with the close relationship that has been previously described between ICP and $\mathrm{P}_{\mathrm{bt}} \mathrm{O}_{2}$ after TBI (75). This improved oxygenation of the brain following administration of the NK1 antagonist may, in part, account for the improved neuronal cell survival and associated improvement on functional outcome previously reported (3).

A number of other experimental compounds have been successfully used to reduce edema formation in experimental TBI studies, including more recently progesterone and magnesium $(4,82)$, both of which have been unsuccessful in clinical trials to date $(83,84)$. Notably, when tested in our sheep model of TBI, our preliminary results also showed that both compounds had little effect on ICP or $\mathrm{P}_{\mathrm{bt}} \mathrm{O}_{2}$ after TBI (unpublished results). The hyperosmotic compound mannitol is used clinically in the management of increased ICP following TBI, although considerable variability has been observed in both the $\operatorname{ICP}(9,85)$ and $\mathrm{P}_{b t} \mathrm{O}_{2}$ response $(86)$ in these clinical studies. The mechanism of action of mannitol is to draw water out of brain tissue into the vasculature where 

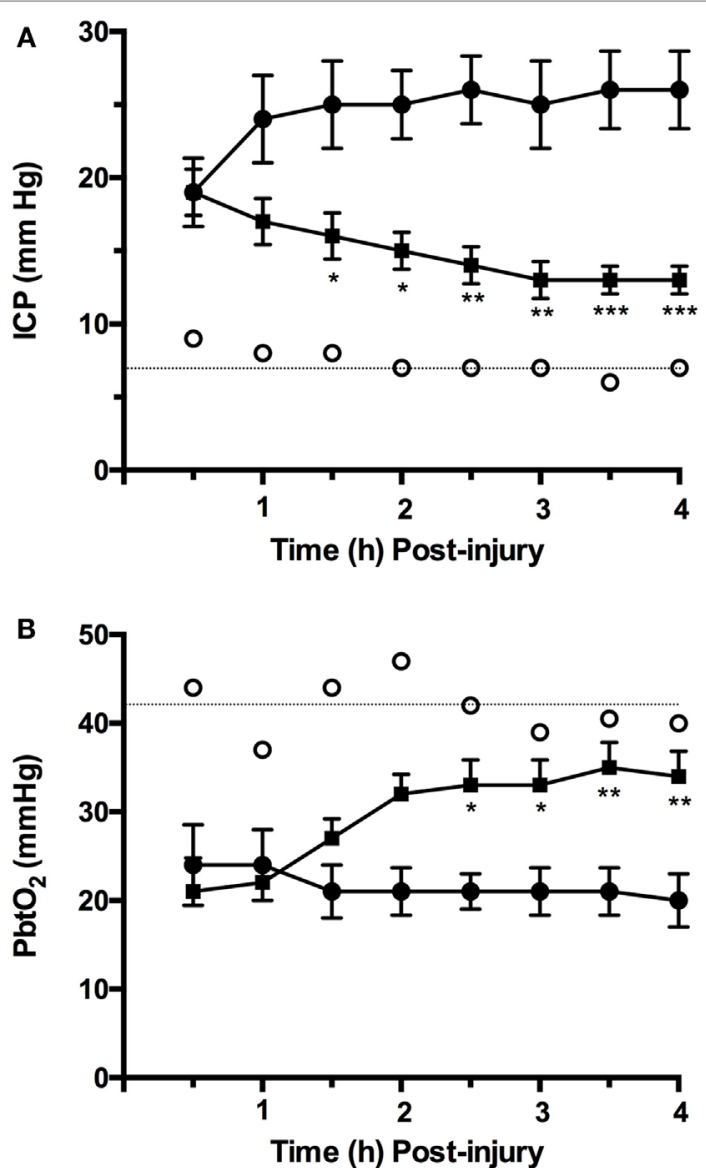

FIGURE 1 | Time course of changes in (A) intracranial pressure (ICP) and (B) $\mathrm{P}_{\mathrm{bt}} \mathrm{O}_{2}$ following moderate to severe diffuse traumatic brain injury in sheep and treatment with an NK1 antagonist [adapted from Ref. (19, 75)]. Briefly, 2-year-old isoflurane anesthetized merino sheep were injured using the humane stunner and monitored for ICP and $\mathrm{P}_{\mathrm{bt}} \mathrm{O}_{2} . \mathrm{N}$-acetyl-L-tryptophan (NAT: $2.5 \mathrm{mg} / \mathrm{kg}$ i.v.) was administered at $30 \mathrm{~min}$ after injury. o = sham (uninjured) animals $(n=9) ; \bullet=$ vehicle (saline) treated animals $(n=9)$; - = NAT-treated animals $(n=10) .{ }^{*} p<0.05 ;{ }^{* \star} p<0.01$; ${ }^{* \star \star} p<0.001$ versus vehicle-treated animals (two-way ANOVA followed by Bonferroni post hoc tests).

its presence has increased the osmotic pressure. This does not attenuate the potential mechanisms driving an increase in ICP, where the BBB after TBI is more permeable to proteins. There is also the potential that mannitol may actually cross into the brain parenchyma through the more permeable $\mathrm{BBB}$, increasing the brain osmotic pressure and causing water influx with a rebound increase in ICP (87). By contrast, the mechanism of action of the NK1 receptor antagonist involves reducing $\mathrm{BBB}$ permeability and inhibiting the development of vasogenic edema (17), thus eliminating any possibility for a rebound increases in ICP.

\section{MECHANISM OF ACTION}

Vasogenic edema occurs when a BBB with increased permeability to vascular protein facilitates the influx of proteins such as albumin into the brain; vascular water subsequently follows down the osmotic gradient that has been created. A number of

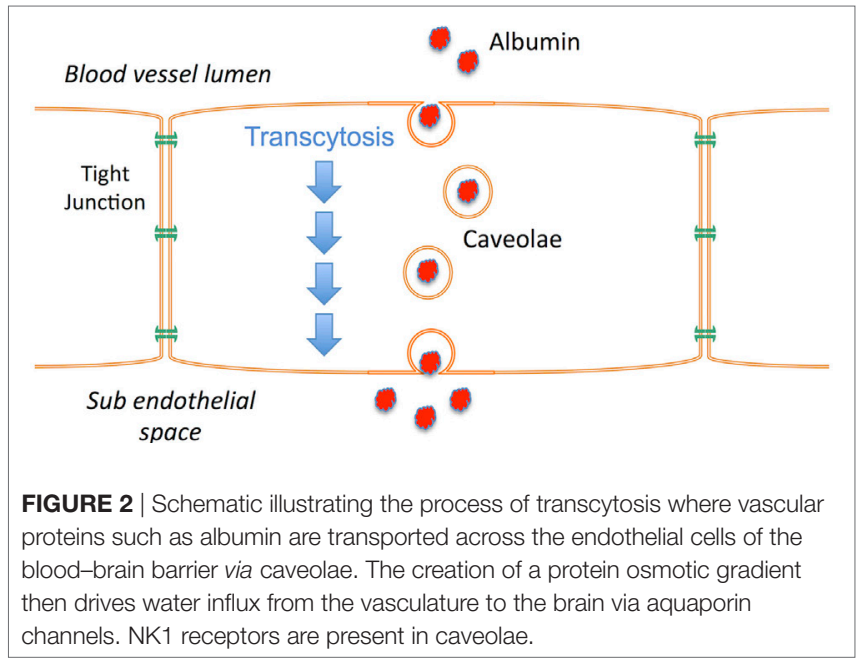

events have been associated with both the early and late BBB disruption described after TBI, including classical inflammation, activation of matrix metalloproteinases, metabolic imbalances, and breakdown of tight junction proteins (88-90). However, the increased movement of proteins across the $\mathrm{BBB}$ does not require the physical breakdown of the barrier or the tight junctions, but rather can occur via caveolae in a process known as transcytosis (91). Indeed, in the hours following TBI, the tight junctions of the BBB have been shown to be intact $(92,93)$ as opposed to the caveolae that are upregulated (93). Increased caveolin-1 expression, a major constituent of caveolae, is thus thought to reflect an increase in albumin transcytosis after TBI (93), and account for the vasogenic edema that ensues (Figure 2). NK1 receptors have been shown to be located in caveolae (94-96), suggesting that their activation may play a role in regulating transcytosis. The fact that NK1 antagonists reduce BBB permeability after TBI, at a time when the tight junctions are intact and the $\mathrm{BBB}$ is more permeable to albumin, supports this suggestion. Thus, the release of perivascular SP after TBI activates NK1 receptors, including those localized to caveolae. This activates transcytotic albumin transport from the vasculature to the brain parenchyma, creating a protein osmotic gradient that drives water entry through aquaporin channels with subsequent edema formation. By inhibiting transcytosis, the NK1 antagonists attenuate the development of an osmotic gradient and negate the requirement for water movement from the vasculature to the brain. Without increased volume from vascular-derived water, there will not be an edemaassociated increase in ICP, and any water that has accumulated in the brain will now be able to efflux via aquaporin channels (97).

\section{CONCLUSION}

NK1 antagonists reduce posttraumatic ICP to near normal levels within a few hours of drug administration. They also restore $\mathrm{P}_{\mathrm{bt}} \mathrm{O}_{2}$ to normal levels in the same time frame, confirming an association between ICP and $\mathrm{P}_{\mathrm{bt}} \mathrm{O}_{2}$ after TBI. The effects of NK1 antagonists on these parameters are more consistent and generally superior to mannitol, without the risk of rebound increases in ICP, and significantly better than the experimental 
treatment strategies progesterone and magnesium, which are ineffective. We posit that SP-mediated increases in protein transcytosis increases vascular permeability, significantly contributing to the development of increased ICP after acute brain injury. Administration of NK1 antagonists reduces this protein transcytosis, eliminating the driver for vasogenic edema and thus reducing increased ICP. Accordingly, the NK1 antagonists warrant further investigation as a novel therapeutic approach to the management of increased ICP.

\section{REFERENCES}

1. Harrison JE, Henley G, Helps Y. Hospital Separations Due to Traumatic Brain Injury, Australia 2004-2005. Canberra: Australian Institute of Health and Welfare (2008)

2. Faul M, Coronado V. Epidemiology of traumatic brain injury. Handb Clin Neurol (2015) 127:3-13. doi:10.1016/B978-0-444-52892-6.00001-5

3. Vink R, Van Den Heuvel C. Substance P antagonists as a therapeutic approach to improving outcome following traumatic brain injury. Neurotherapeutics (2010) 7(1):74-80. doi:10.1016/j.nurt.2009.10.018

4. Vink R, Nimmo AJ. Multifunctional drugs for head injury. Neurotherapeutics (2009) 6(1):28-42. doi:10.1016/j.nurt.2008.10.036

5. Loane DJ, Faden AI. Neuroprotection for traumatic brain injury: translational challenges and emerging therapeutic strategies. Trends Pharmacol Sci (2010) 31(12):596-604. doi:10.1016/j.tips.2010.09.005

6. Marmarou A. A review of progress in understanding the pathophysiology and treatment of brain edema. Neurosurg Focus (2007) 22(5):E1. doi:10.3171/ foc.2007.22.4.2

7. Feickert HJ, Drommer S, Heyer R. Severe head injury in children: impact of risk factors on outcome. JTrauma (1999) 47(1):33-8. doi:10.1097/ 00005373-199907000-00008

8. Rowlands EL, Morris KP. Management of severe traumatic brain injury. Paediatr Child Health (2007) 17:82-8. doi:10.1016/j.paed.2007.01.011

9. Meyer MJ, Megyesi J, Meythaler J, Murie-Fernandez M, Aubut J, Foley N, et al. Acute management of acquired brain injury part II: an evidence-based review of pharamcological interventions. Brain Injury (2010) 24(5):706-21. doi:10.3109/02699051003692126

10. Czosnyka M, Pickard JD, Steiner LA. Principles of intracranial pressure monitoring and treatment. Handb Clin Neurol (2017) 140:67-89. doi:10.1016/ B978-0-444-63600-3.00005-2

11. Simard JM, Kent TA, Chen M, Tarasov KV, Gerzanich V. Brain oedema in focal ischaemia: molecular pathophysiology and theoretical implications. Lancet Neurol (2007) 6(3):258-68. doi:10.1016/S1474-4422(07)70055-8

12. Donkin JJ, Vink R. Mechanisms of cerebral edema in traumatic brain injury: therapeutic developments. Curr Opin Neurol (2010) 23(3):293-9. doi:10.1097/ WCO.0b013e328337f451

13. Beaumont A, Marmarou A, Hayasaki K, Barzo P, Fatouros P, Corwin F, et al. The permissive nature of blood brain barrier (BBB) opening in edema formation following traumatic brain injury. Acta Neurochir Suppl (2000) 76:125-9. doi: 10.1007/978-3-7091-6346-7_26

14. Cabella B, Donnelly J, Cardim D, Liu X, Cabeleira M, Smielewski P, et al. An association between ICP-derived data and outcome in TBI patients: the role of sample size. Neurocrit Care (2017). doi:10.1007/s12028-016-0319-x

15. Corrigan F, Mander KA, Leonard AV, Vink R. Neurogenic inflammation after traumatic brain injury and its potentiation of classical inflammation. J Neuroinflammation (2016) 13(1):264. doi:10.1186/s12974-016-0738-9

16. Donkin JJ, Turner RJ, Hassan I, Vink R. Substance P in traumatic brain injury. Prog Brain Res (2007) 161:97-109. doi:10.1016/S0079-6123(06)61007-8

17. Donkin JJ, Nimmo AJ, Cernak I, Blumbergs PC, Vink R. Substance P is associated with the development of brain edema and functional deficits after traumatic brain injury. J Cereb Blood Flow Metab (2009) 29(8):1388-98. doi:10.1038/jcbfm.2009.63

18. Turner RJ, Helps SC, Thornton E, Vink R. A substance P antagonist improves outcome when administered $4 \mathrm{~h}$ after onset of ischemic stroke. Brain Res (2011) 1393:84-90. doi:10.1016/j.brainres.2011.03.066

19. Gabrielian L, Helps SC, Thornton E, Turner RJ, Leonard AV, Vink R. Substance $\mathrm{P}$ antagonists as a novel intervention for brain edema and raised

\section{AUTHOR CONTRIBUTIONS}

RV drafted the manuscript and prepared all of the figures. LG and ET contributed to Figure 1 and drafted sections of the manuscript.

\section{FUNDING}

This study was supported by grants to RV from the National Health and Medical Research Council, Australia.

intracranial pressure. Acta Neurochir Suppl (2013) 118:201-4. doi:10.1007/ 978-3-7091-1434-6_37

20. Leeman SE, Ferguson SL. Substance P: an historical perspective. Neuropeptides (2000) 34(5):249-54. doi:10.1054/npep.2000.0826

21. Maggi CA. The mammalian tachykinin receptors. Gen Pharmacol (1995) 26(5):911-44. doi:10.1016/0306-3623(94)00292-U

22. Hokfelt T, Pernow B, Wahren J. Substance P: a pioneer amongst neuropeptides. J Intern Med (2001) 249(1):27-40. doi:10.1046/j.0954-6820.2000.00773.x

23. Hokfelt T, Kellerth JO, Nilsson G, Pernow B. Substance P: localisation in the central nervous system and in some primary sensory neurones. Science (1975) 190(4217):889-90. doi:10.1126/science.242075

24. Vennekens R, Menigoz A, Nilius B. TRPs in the brain. Rev Physiol Biochem Pharmacol (2012) 163:27-64. doi: 10.1007/112_2012_8

25. Saffroy M, Torrens Y, Glowinski J, Beaujouan JC. Autoradiographic distribution of tachykinin NK2 binding sites in the rat brain: comparison with NK1 and NK3 binding sites. Neuroscience (2003) 116(3):761-73. doi:10.1016/ S0306-4522(02)00748-0

26. Krause JE, Chirgwin JM, Carter MS, Xu ZS, Hershey AD. Three rat preprotachykinin mRNAs encode the neuropeptides substance $\mathrm{P}$ and neurokinin A. Proc Natl Acad Sci U S A (1987) 84(3):881-5. doi:10.1073/pnas.84.3.881

27. Kotani H, Hoshimaru M, Nawa H, Nakanishi S. Structure and gene organization of bovine neuromedin K precursor. Proc Natl Acad Sci U S A (1986) 83(18):7074-8. doi:10.1073/pnas.83.18.7074

28. Harrison S, Geppetti P. Substance p. Int J Biochem Cell Biol (2001) 33(6): 555-76. doi:10.1016/S1357-2725(01)00031-0

29. Matsas R, Kenny AJ, Turner AJ. The metabolism of neuropeptides. The hydrolysis of peptides, including enkephalins, tachykinins and their analogues, by endopeptidase-24.11. Biochem J (1984) 223(2):433-40. doi:10.1042/ bj2230433

30. Skidgel RA, Erdos EG. Cleavage of peptide bonds by angiotensin I converting enzyme. Agents Actions Suppl (1987) 22:289-96.

31. Probert L, Hanley MR. The immunocytochemical localisation of 'substance-P-degrading enzyme' within the rat spinal cord. Neurosci Lett (1987) 78(2):132-7. doi:10.1016/0304-3940(87)90621-5

32. Blumberg S, Teichberg VI, Charli JL, Hersh LB, McKelvy JF. Cleavage of substance $\mathrm{P}$ to an $\mathrm{N}$-terminal tetrapeptide and a C-terminal heptapeptide by a post-proline cleaving enzyme from bovine brain. Brain Res (1980) 192(2):477-86. doi:10.1016/0006-8993(80)90898-7

33. Heymann E, Mentlein R. Liver dipeptidyl aminopeptidase IV hydrolyzes substance P. FEBS Lett (1978) 91(2):360-4. doi:10.1016/0014-5793(78)81210-1

34. Azaryan AV, Galoyan AA. Substrate specificity of cerebral cathepsin D and high-Mr aspartic endopeptidase. J Neurosci Res (1988) 19(2):268-71. doi:10.1002/jnr.490190213

35. Kageyama T. Rabbit procathepsin E and cathepsin E. Nucleotide sequence of cDNA, hydrolytic specificity for biologically active peptides and gene expression during development. Eur J Biochem (1993) 216(3):717-28. doi:10.1111/j.1432-1033.1993.tb18191.x

36. Nadel JA. Neutral endopeptidase modulates neurogenic inflammation. Eur Respir J (1991) 4(6):745-54.

37. Hooper NM, Turner AJ. Isolation of two differentially glycosylated forms of peptidyl-dipeptidase A (angiotensin converting enzyme) from pig brain: a re-evaluation of their role in neuropeptide metabolism. Biochem J (1987) 241(3):625-33. doi:10.1042/bj2410625

38. Sakurada T, Hara A, Matsumura H, Yamada H, Sakurada S, Kisara K. A substance $\mathrm{P}$ analogue reduces amino acid contents in the rat spinal cord. Pharmacol Toxicol (1990) 66(1):75-6. doi:10.1111/j.1600-0773.1990.tb00708.x 
39. Di Maria GU, Bellofiore S, Geppetti P. Regulation of airway neurogenic inflammation by neutral endopeptidase. Eur Respir J (1998) 12(6):1454-62. doi:10.1183/09031936.98.12061454

40. Wang LH, Ahmad S, Benter IF, Chow A, Mizutani S, Ward PE. Differential processing of substance $\mathrm{P}$ and neurokinin A by plasma dipeptidyl(amino) peptidase IV, aminopeptidase $\mathrm{M}$ and angiotensin converting enzyme. Peptides (1991) 12(6):1357-64. doi:10.1016/0196-9781(91)90220-J

41. Shults CW, Quirion R, Chronwall B, Chase TN, O'Donohue TL. A comparison of the anatomical distribution of substance $\mathrm{P}$ and substance P receptors in the rat central nervous system. Peptides (1984) 5(6):1097-128. doi:10.1016/0196-9781(84)90177-3

42. Helke CJ. Neuroanatomical localization of substance p: implications for central cardiovascular control. Peptides (1982) 3(3):479-83. doi:10.1016/ 0196-9781(82)90111-5

43. Helke CJ, Neil JJ, Massari VJ, Loewy AD. Substance P neurons project from the ventral medulla to the intermediolateral cell column and ventral horn in the rat. Brain Res (1982) 243(1):147-52. doi:10.1016/0006-8993(82)91128-3

44. Bergner AJ, Murphy SM, Anderson CR. After axotomy, substance P and vasoactive intestinal peptide expression occurs in pilomotor neurons in the rat superior cervical ganglion. Neuroscience (2000) 96(3):611-8. doi:10.1016/ S0306-4522(99)00576-X

45. Lee Y, Kawai Y, Shiosaka S, Takami K, Kiyama H, Hillyard CJ, et al. Coexistence of calcitonin gene-related peptide and substance P-like peptide in single cells of the trigeminal ganglion of the rat: immunohistochemical analysis. Brain Res (1985) 330(1):194-6. doi:10.1016/0006-8993(85)90027-7

46. Gibbins IL, Furness JB, Costa M. Pathway-specific patterns of the co-existence of substance $\mathrm{P}$, calcitonin gene-related peptide, cholecystokinin and dynorphin in neurons of the dorsal root ganglia of the guinea-pig. Cell Tissue Res (1987) 248(2):417-37. doi:10.1007/BF00218210

47. Sternini C, Su D, Gamp PD, Bunnett NW. Cellular sites of expression of the neurokinin-1 receptor in the rat gastrointestinal tract. J Comp Neurol (1995) 358(4):531-40. doi:10.1002/cne.903580406

48. Dun NJ, Minota S. Effects of substance P on neurones of the inferior mesenteric ganglia of the guinea-pig. J Physiol (1981) 321:259-71. doi:10.1113/ jphysiol.1981.sp013982

49. Marlier L, Poulat P, Rajaofetra N, Privat A. Modifications of serotonin-, substance $\mathrm{P}$ - and calcitonin gene-related peptide-like immunoreactivities in the dorsal horn of the spinal cord of arthritic rats: a quantitative immunocytochemical study. Exp Brain Res (1991) 85(3):482-90. doi:10.1007/ BF00231731

50. Schaible HG, Jarrott B, Hope PJ, Duggan AW. Release of immunoreactive substance $\mathrm{P}$ in the spinal cord during development of acute arthritis in the knee joint of the cat: a study with antibody microprobes. Brain Res (1990) 529(1-2):214-23. doi:10.1016/0006-8993(90)90830-5

51. Hokfelt T, Zhang X, Wiesenfeld-Hallin Z. Messenger plasticity in primary sensory neurons following axotomy and its functional implications. Trends Neurosci (1994) 17(1):22-30. doi:10.1016/0166-2236(94)90031-0

52. Noguchi K, Morita Y, Kiyama H, Ono K, Tohyama M. A noxious stimulus induces the preprotachykinin-A gene expression in the rat dorsal root ganglion: a quantitative study using in situ hybridization histochemistry. Brain Res (1988) 464(1):31-5. doi:10.1016/0169-328X(88)90015-0

53. McCarson KE. Central and peripheral expression of neurokinin-1 and neurokinin-3 receptor and substance P-encoding messenger RNAs: peripheral regulation during formalin-induced inflammation and lack of neurokinin receptor expression in primary afferent sensory neurons. Neuroscience (1999) 93(1):361-70. doi:10.1016/S0306-4522(99)00102-5

54. Black PH. Stress and the inflammatory response: a review of neurogenic inflammation. Brain Behav Immun (2002) 16(6):622-53. doi:10.1016/ S0889-1591(02)00021-1

55. Seybold VS, McCarson KE, Mermelstein PG, Groth RD, Abrahams LG. Calcitonin gene-related peptide regulates expression of neurokinin 1 receptors by rat spinal neurons. J Neurosci (2003) 23(5):1816-24.

56. Corrigan F, Vink R, Turner RJ. Inflammation in acute CNS injury: a focus on the role of substance P. Br J Pharmacol (2016) 173(4):703-15. doi:10.1111/ bph.13155

57. Markowitz S, Saito K, Moskowitz MA. Neurogenically mediated leakage of plasma protein occurs from blood vessels in Dura mater but not brain. J Neurosci (1987) 7(12):4129-36.
58. Stumm R, Culmsee C, Schafer MK, Krieglstein J, Weihe E. Adaptive plasticity in tachykinin and tachykinin receptor expression after focal cerebral ischemia is differentially linked to gabaergic and glutamatergic cerebrocortical circuits and cerebrovenular endothelium. J Neurosci (2001) 21(3):798-811.

59. Cyrino LA, Cardoso RC, Hackl LP, Nicolau M. Effect of quercetin on plasma extravasation in rat CNS and dura mater by ACE and NEP inhibition. Phytother Res (2002) 16(6):545-9. doi:10.1002/ptr.987

60. Vink R, Young A, Bennett CJ, Hu X, Connor CO, Cernak I, et al. Neuropeptide release influences brain edema formation after diffuse traumatic brain injury. Acta Neurochir Suppl (2003) 86:257-60. doi:10.1007/978-3-7091-0651-8_55

61. Nimmo AJ, Cernak I, Heath DL, Hu X, Bennett CJ, Vink R. Neurogenic inflammation is associated with development of edema and functional deficits following traumatic brain injury in rats. Neuropeptides (2004) 38(1):40-7. doi:10.1016/j.npep.2003.12.003

62. Harford-Wright E, Thornton E, Vink R. Angiotensin-converting enzyme (ACE) inhibitors exacerbate histological damage and motor deficits after experimental traumatic brain injury. Neurosci Lett (2010) 481(1):26-9. doi:10.1016/j.neulet.2010.06.044

63. Turner RJ, Blumbergs PC, Sims NR, Helps SC, Rodgers KM, Vink R. Increased substance P immunoreactivity and edema formation following reversible ischemic stroke. Acta Neurochir Suppl (2006) 96:263-6. doi:10.1007/3-211-30714-1_56

64. Leonard AV, Thornton E, Vink R. Substance P as a mediator of neurogenic inflammation after balloon compression induced spinal cord injury. J Neurotrauma (2013) 30(21):1812-23. doi:10.1089/neu.2013.2993

65. Leonard AV, Manavis J, Blumbergs PC, Vink R. Changes in substance P and NK1 receptor immunohistochemistry following human spinal cord injury. Spinal Cord (2014) 52(1):17-23. doi:10.1038/sc.2013.136

66. Hu DE, Easton AS, Fraser PA. TRPV1 activation results in disruption of the blood-brain barrier in the rat. Br J Pharmacol (2005) 146(4):576-84. doi:10.1038/sj.bjp.0706350

67. Zacest AC, Vink R, Manavis J, Sarvestani GT, Blumbergs PC. Substance $\mathrm{P}$ immunoreactivity increases following human traumatic brain injury. Acta Neurochir Suppl (2010) 106:211-6. doi:10.1007/978-3-211-98811-4_39

68. Cook NL, Vink R, Donkin JJ, van den Heuvel C. Validation of reference genes for normalization of real-time quantitative RT-PCR data in traumatic brain injury. J Neurosci Res (2009) 87(1):34-41. doi:10.1002/jnr.21846

69. Lorente L, Martin MM, Almeida T, Hernandez M, Ramos L, Argueso M, et al. Serum substance $P$ levels are associated with severity and mortality in patients with severe traumatic brain injury. Crit Care (2015) 19:192. doi:10.1186/ s13054-015-0911-z

70. Donkin JJ, Cernak I, Blumberg PC, Vink R. A substance P antagonist reduces axonal injury and improves neurologic outcome when administered up to 12 hours after traumatic brain injury. J Neurotrauma (2011) 28(2):218-24. doi:10.1089/neu.2010.1632

71. Corrigan F, Leonard A, Ghabriel M, Van Den Heuvel C, Vink R. A substance $\mathrm{P}$ antagonist improves outcome in female Sprague Dawley rats following diffuse traumatic brain injury. CNS Neurosci Ther (2012) 18(6):513-5. doi:10.1111/j.1755-5949.2012.00332.x

72. Turner RJ, Vink R. NK1 tachykinin receptor treatment is superior to capsaicin pre-treatment in improving functional outcome following acute ischemic stroke. Neuropeptides (2014) 48(5):267-72. doi:10.1016/j.npep.2014.07.002

73. Turner RJ, Vink R. Combined tissue plasminogen activator and an NK1 tachykinin receptor antagonist: an effective treatment for reperfusion injury following acute ischemic stroke in rats. Neuroscience (2012) 220:1-10. doi:10.1016/j.neuroscience.2012.06.047

74. CernakI.Animalmodels of headtrauma.Neurotherapeutics(2005)2(3):410-22. doi:10.1602/neurorx.2.3.410

75. Vink R, Bhatia KD, Reilly PL. The relationship between intracranial pressure and brain oxygenation following traumatic brain injury in sheep. Acta Neurochir Suppl (2008) 102:189-92. doi:10.1007/978-3-211-85578-2_37

76. Byard RW, Gabrielian L, Helps SC, Thornton E, Vink R. Further investigations into the speed of cerebral swelling following blunt cranial trauma. J Forensic Sci (2012) 57(4):973-5. doi:10.1111/j.1556-4029.2012.02109.x

77. Klintworth GK. The comparative anatomy and phylogeny of the tentorium cerebelli. Anat Rec (1968) 160(3):635-42. doi:10.1002/ar.1091600312

78. Gabrielian L, Willshire LW, Helps SC, van den Heuvel C, Mathias JL, Vink R. Intracranial pressure changes following traumatic brain injury in rats: lack of 
significant change in the absence of mass lesions or hypoxia. J Neurotrauma (2011) 28(10):2103-11. doi:10.1089/neu.2011.1785

79. O'Connor CA, Cernak I, Vink R. The temporal profile of edema formation differs between male and female rats following diffuse traumatic brain injury. Acta Neurochir Suppl (2006) 96:121-4. doi:10.1007/3-21130714-1_27

80. Byard RW, Bhatia KD, Reilly PL, Vink R. How rapidly does cerebral swelling follow trauma? Observations using an animal model and possible implications in infancy. Leg Med (Tokyo) (2009) 11(Suppl 1):S128-31. doi:10.1016/j. legalmed.2009.02.001

81. Gabrielian L. Development of Novel Pharmacological Treatments for Intracranial Pressure Using Appropriate Experimental Models of Traumatic Brain Injury. $\mathrm{PhD}$, University of Adelaide, Adelaide, Australia (2013).

82. Stein DG, Fulop Z. Progesterone and recovery after traumatic brain injury: an overview. Neuroscientist (1998) 4:435-42. doi:10.1177/ 107385849800400615

83. Li W, Bai YA, Li YJ, Liu KG, Wang MD, Xu GZ, et al. Magnesium sulfate for acute traumatic brain injury. J Craniofac Surg (2015) 26(2):393-8. doi:10.1097/ SCS. 0000000000001339

84. Ma J, Huang S, Qin S, You C, Zeng Y. Progesterone for acute traumatic brain injury. Cochrane DatabaseSyst Rev (2016) 12:Cd008409. doi:10.1002/14651858. CD008409.pub4

85. Brain Trauma Foundation. Hyperosmolar therapy. J Neurotrauma (2007) 24(Suppl 1):14-20. doi:10.1089/neu.2007.9994

86. Bohman LE, Heuer GG, Macyszyn L, Maloney-Wilensky E, Frangos S, Le Roux PD, et al. Medical management of compromised brain oxygen in patients with severe traumatic brain injury. Neurocrit Care (2011) 14(3):361-9. doi:10.1007/s12028-011-9526-7

87. Node Y, Nakazawa S. Clinical study of mannitol and glycerol on raised intracranial pressure and on their rebound phenomenon. Adv Neurol (1990) 52:359-63.

88. Nag S, Manias JL, Stewart DJ. Pathology and new players in the pathogenesis of brain edema. Acta Neuropathol (2009) 118(2):197-217. doi:10.1007/ s00401-009-0541-0

89. Shlosberg D, Benifla M, Kaufer D, Friedman A. Blood-brain barrier breakdown as a therapeutic target in traumatic brain injury. Nat Rev Neurol (2010) 6(7):393-403. doi:10.1038/nrneurol.2010.74
90. Prakash R, Carmichael ST. Blood-brain barrier breakdown and neovascularization processes after stroke and traumatic brain injury. Curr Opin Neurol (2015) 28(6):556-64. doi:10.1097/WCO.0000000000000248

91. Abbott NJ, Ronnback L, Hansson E. Astrocyte-endothelial interactions at the blood-brain barrier. Nat Rev Neurosci (2006) 7(1):41-53. doi:10.1038/nrn1824

92. Povlishock JT, Becker DP, Sullivan HG, Miller JD. Vascular permeability alterations to horseradish peroxidase in experimental brain injury. Brain Res (1978) 153(2):223-39. doi:10.1016/0006-8993(78)90404-3

93. Nag S, Venugopalan R, Stewart DJ. Increased caveolin-1 expression precedes decreased expression of occludin and claudin-5 during blood-brain barrier breakdown. Acta Neuropathol (2007) 114(5):459-69. doi:10.1007/ s00401-007-0274-x

94. Monastyrskaya K, Hostettler A, Buergi S, Draeger A. The NK1 receptor localizes to the plasma membrane microdomains, and its activation is dependent on lipid raft integrity. J Biol Chem (2005) 280(8):7135-46. doi:10.1074/jbc. M405806200

95. Meyer BH, Segura JM, Martinez KL, Hovius R, George N, Johnsson K, et al. FRET imaging reveals that functional neurokinin-1 receptors are monomeric and reside in membrane microdomains of live cells. Proc Natl Acad Sci U S A (2006) 103(7):2138-43. doi:10.1073/pnas.0507686103

96. Kubale V, Abramovic Z, Pogacnik A, Heding A, Sentjurc M, Vrecl M. Evidence for a role of caveolin-1 in neurokinin-1 receptor plasma-membrane localization, efficient signaling, and interaction with beta-arrestin 2. Cell Tissue Res (2007) 330(2):231-45. doi:10.1007/s00441-007-0462-y

97. Saadoun S, Papadopoulos MC. Aquaporin-4 in brain and spinal cord oedema. Neuroscience (2010) 168(4):1036-46. doi:10.1016/j.neuroscience.2009.08.019

Conflict of Interest Statement: The authors declare that the research was conducted in the absence of any commercial or financial relationships that could be construed as a potential conflict of interest.

Copyright $(\odot 2017$ Vink, Gabrielian and Thornton. This is an open-access article distributed under the terms of the Creative Commons Attribution License (CC BY). The use, distribution or reproduction in other forums is permitted, provided the original author(s) or licensor are credited and that the original publication in this journal is cited, in accordance with accepted academic practice. No use, distribution or reproduction is permitted which does not comply with these terms. 